\title{
The System of the Methodological Principles of Management of Enterprise Development
}

\author{
Iskandar Souleiman Kobersy 1 \\ Karine Alexandrovna Barmuta1 \\ Safoura Shokhovna Muradova1 \\ Ludmila Ivanovna Dubrova ${ }^{1}$ \\ Dmitry Shkurkin² \\ ${ }^{1}$ Don state technical University (DSTU), Rostov-on-Don, Russia \\ 2Limited Liability Company «ELDirect» \\ E-mail: carinaba@yandex.ru
}

Doi:10.5901/mjss.2015.v6n3s4p25

Abstract

Currently, economic growth economic entities more and more dependent on enterprise adaptation to the changing needs of the market environment to the products manufactured by the company. In these circumstances, it is important to understand and determine what should be the methodology of construction of the control system based on an innovative approach. During the formation of the mechanism of management of the company needs to follow a number of methodological principles of management of development of the enterprise. The proposed conceptual methodological principles of formation of the system of management of development of the enterprise with the purpose of increase of efficiency of functioning and quality of production. System conceptual methodological principles of formation of the system of effective management of enterprise development, according to the authors, should be based on the following research approaches: integration, task, system, complex, situational, economic, synergistic. The synergetic approach to managing effective enterprise development based on the principles of self-organization and self-development systems, openness of the enterprise for innovation and transformation.

Keywords: business management, synergy, principles of management.

\section{Introduction}

The development of industry, as it is known, is closely related to scientific and technical progress and implementation of its results in production. The implementation of this installation is not possible without the improvement of the management system based on the innovative nature of its development (Olufemi, Caleb \& Akinjare, 2012).

In Russia there is a formation of national and regional innovation systems. In the era of the "knowledge economy" innovation has become a major factor in improving the efficiency of industrial enterprises. The solution of large-scale objectives requires a comprehensive critical analysis and review their approaches, establishing the theoretical foundations for the effective development of industrial enterprises.

Today, the economic growth of businesses, as you know, more and more dependent on enterprise adaptation to the changing needs of the market environment to the products manufactured by the company. In these circumstances, it is important to understand and determine what should be the methodology of construction of the control system based on an innovative approach. It is no accident in the scientific literature the development of the methodology to improve the efficiency of management pays great attention from both foreign and domestic scientists.

However, for the majority of works are characterized by the absence of a systematic approach, sufficient to link the development of industrial enterprises with the requirements of the market economic system.

Overcoming the economic crisis in the industry of Russia should be considered as an additional incentive for industry to realize the potential of development and economic growth through the introduction of innovative technologies in the sphere of production and management, allowing you to increase the intensity of use of limited resources and, thus, to successfully solve the basic problem of economic development of enterprises and the region in which they are located (Lefter \& Brătianu, 2001).

The main characteristic of any socio-economic system, be it a company, region, state overall, at the present time is 
determined through the development, i.e. significant, necessary move, change anything in time (Barmouth, K. A., 2010). This notion characterizes qualitative changes of objects, the emergence of new forms of being, the transformation of their internal and external relations.

Development as a separate process has the following stages: the first involves the preparation prerequisites for the formation of this process, it is basically the movement; the second is the transition to internal movement; the third is the formation, transformation of the new process conditions from which it arose; the fourth is the actual development, sustainable existence on its basis; the fth is the destruction process.

Development is about empowerment, capacity and has no limitations. In this sense, the development is effective redistribution of resources, primarily investment in areas that provide the highest possible competitive for the longest period, improvement of goods and services, including, and on the basis of the existing organizational structure, improving the structure and management systems, the result of which is the increased demand for the company's products and its broader economic activity. Thus, the development of both qualitative change of the object can take different forms: the transformation, the origin, formation, destruction, formation of the new form or structure, the transformation of the content, relationships and dependencies, etc.

With the development of market relations in Russia, it becomes clear that in order to achieve efficient operation, while remaining under the previous system of enterprise management is impossible. The specificity of the market economy, mentality and cultural differences between Russia do not allow to use Western methods of enterprise management. For this reason requires the development and application of modern approaches to management, more appropriate to the economic situation in Russia. Management in market conditions means, above all, the orientation of the enterprise on demand and market demand, constant desire to improve production efficiency, the search for new opportunities to obtain the best results at the lowest cost.

\section{The System of the Methodological Principles of Management of Enterprise Development}

One of the main objectives of industrial development is the formation mechanism of managerial decision-making at the enterprise level to improve the functioning and quality of production. The problem of ensuring the effective development of enterprises due to the General financial-economic problems of the economy, the interaction of market participants, the organization of industrial relations in the activity of enterprises.

The formation mechanism for the effective management of enterprise development requires justification, and follow certain methodological principles. To make the process of managing the development of industrial enterprises logical completeness, structure and required performance, it is necessary to follow a number of methodological principles of management of development of the enterprise.

Nonlinear, non-equilibrium, irreversible nature of economic processes in the medium and the historical time scale was marked by some economists scientific schools in the nineteenth century. In today's business world, traditional management science less corresponds to the practical interests of managers, because it focuses on the analysis, prediction and management. The experience of the last 20 years has shown that in the new situation, using well-known principles leads to disaster. In a rapidly changing markets, the desire for the quantitative description of social phenomena (quantification) to work, labour, the separation of planning from execution, isolation of workers from each other creates such an organizational structure, which is difficult in a short time to adapt to the ongoing changes.

System conceptual methodological principles of management of development of the enterprise should be based on the following research approaches: integration, task, system, complex, situational, economic, synergistic (added by authors) (Fig. 1). 


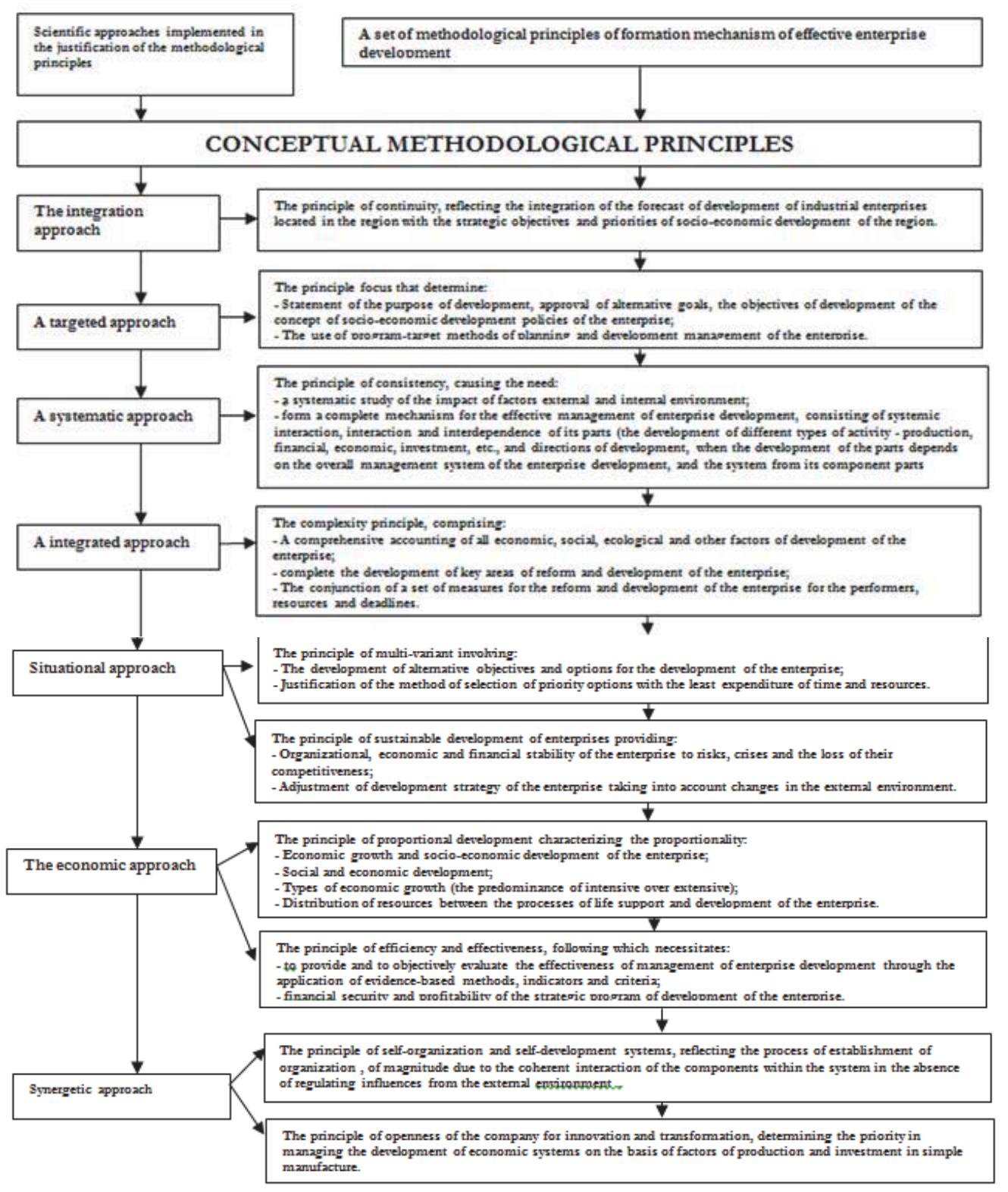

Figure 1. The system of the methodological principles of management of enterprise development

Accordingly allocated approaches have inherent principles of management of enterprise development: an integration approach - the principle of continuity, the target is the principle focus of the system - the principle of consistency, the complex - the principle of a complex, situation - principles of multi-variant and sustainable development of the enterprise, economic - principles of proportional development, efficiency and effectiveness, synergy - the principles of selforganization and self-development systems and openness of the enterprise for innovation and transformation.

Following the principles in practice will lead to successful structuring processes of development management of the company and to implement them effectively.

\section{The Essence of a Synergistic Approach}

Development is a phase, structural, vector transformation in space and time, resulting in the formation of a new paradigm in economic theory based on the theory of self-organization and synergetic. Spend rationale for selection of the authors of the study synergistic approach. 
Synergetic management is regarded as a technology development management at different levels of economic systems from a global, sectorial, and corporate, regional to nano (the level of the individual and the household). The need for synergy management is critical due to the ambiguity of the processes that occur in the economy and economic theory in Russia.

Synergetic management focuses on accelerated development, break through the formation in systems of synergy effects, the creation of new products, new markets, new economic environment.

The ability to form and implement synergies considered in the synergetic management as a core competence required of the Manager of the XXI century.

The term "synergy" was introduced into science in the nineteenth century, the English physiologist Charles S. Operators to describe the cooperative action of the muscular system, controlled by the brain. Later this term was widely used in physiology to denote the joint behavior. In the last time "synergetic" became known as the theory of joint action, based on the General laws of self-organization in nonlinear dynamical systems of different nature.

The essence of self-organization is that the space with an infinite number of measurements produces a relatively small number of simple entities. In the basis of the theory of self-organization is the principle of development. The Foundation concepts of self-organization are today synergetic and the theory of change. Synergetic (by Herman Haken) is a heuristic study of open self-organizing systems, subject to the cooperative effect which is accompanied by the formation of spatial, temporal or functional structures, i.e. the processes of self-organization of systems of different nature. Theory of change (Brussels school, her representative - Prigogine I. R.) is a heuristic methodology and appropriate conceptual framework for studying the processes of movement systems, particularly phase "jump".

Developed management system of enterprise development is most effective when it has absorbed the entire previous experience of the many different currents and scientifically advanced. The new control system has the deep roots that originated in the early twentieth century. Therefore, at the present stage of development in the management activities required in-depth knowledge of the laws governing the evolution of the world, goals, motives of human development, and, more importantly, the mechanism of realization of these goals.

Control theory can and should use the latest results of the natural and social Sciences that are associated with the effects of self-organization and enrich your system theory with new concepts: dynamic chaos, operational closure, samariterstrasse, contingently (Bogomolov, N. In., 2007).

The strategic and tactical issues in the enterprise today include effective management of the development. The main task of the modern leader is to learn how to create opportunities and not be limited to solving problems.

An essential feature of the management process is the processing of information, establishing feedback. This control can be accomplished in two ways spontaneously and consciously. The first impact is the result of interaction of subjects (synergetic management). The second is the result of systematic exposure of the object (hierarchy of control). Thus, we can conclude that management is the process of taking the system to a new level as a result of the impact of energy on matter in a certain space of existence during the realization of the goal.

Existing and evolving management system enterprise development is designed to improve the efficiency of their operations and to create conditions for solving the tasks. This is possible by introducing investigated innovative management technologies, which are based on universal laws of system relationships, developed new educational programs that reveal the ability and initiative of the individual in finding innovative solutions in the system of collective, public and international co-creation of people (Kazantsev, A. K., 2008). In modern management is not an automatism, and autonomy, identity, and difference, not the elements and relations between them, not balance and instability, not Genesis, and permanent formation.

Considering the industrial enterprise as complex, living organism, it is possible to assert the following: the main objectives of the existence of the enterprises survival and development; the main structural principles are self-similarity and self-organization; information is one of the most important elements in the creation, existence and development of enterprises. Complex systems cannot be imposed on their development, and the need to ensure self-development, properly organizing effects in space, time and scale.

Changes in technology, public institutions and values are the main driving forces of the revolution. The result is a completely new society, new ways of organization and disorganization of labor. Well-organized and privately owned human brain outweighs traditional means of production: raw materials, heavy labor and capital.

If we consider the enterprise as an object consisting of many interrelated elements, it is characterized by some specific system property, which is no part of it at any way of partitioning. The enterprise as a system has an input (multiple inputs) through which the external environment impacts on the enterprise, and the output (multiple outputs) through which the company affects the environment. Based on the dependence of output to input, the enterprise can be classified as a complex system whose output is ambiguous functional dependence of the entrance. The enterprise as a 
complex system has a special, phenomenal properties:

- For complex systems no arbitrarily detailed understanding of the structure (morphology) is not sufficient to determine the effects of inlet to outlet, and, conversely, no, whatever detailed knowledge of the mode of exposure input to output does not allow to reveal the morphology;

- Complex systems are self-contained (internal) time scale than astronomical. All processes occur in the Autonomous time-scale; from the perspective of an external observer, they may seem too fast or too slow. Offline, the time scale can be changed;

- Complex systems have their own Autonomous system of units in which they can be quantitatively described. Unit's Autonomous systems are interconnected and linked to physical units using conversion factors;

- Complex systems have a standalone metric, which may differ significantly from the metric of the external environment. Metric difference imposes significant restrictions on the interaction with the environment, but favors the preservation of the system when conditions change. Sometimes Autonomous metric determines the mode of existence of the system (i.e. the system property);

- Synergistic complex systems, the processes of self-organization and self-development. They are in disequilibrium and irreversible. Thanks to the synergy they have high stability and resistance to external influences. However in complex systems (under certain conditions) may be the processes of autonomization of individual structures;

- Development of complex systems can occur through either capacity or complications (if self-preservation and sustainability), or to divide the system into parts (parts Department). Each part is to further develop itself, independently of the other or cooperative;

- complex systems, as a rule, experience periods of "inception", "childhood", "youth", "maturity", "aging", "death". Unlimited stagnating system.

The program conduct business as a system formed either genetically (passed), or synergistic (through selforganization). Genetic program can generate synergistic processes, eliminates or fixed genome, and synergistic processes can create a genetic program that will be fixed and will be able to generate the corresponding synergy. Synergistic programs quite often, but the effect is relatively short. The sequence of synergic programs (due to the influence of the background) is more or less close to the guiding functions (if there is no cataclysms). In principle, synergistic programs can be created by external influences - in interaction systems. Genetic program evolutionizing under the influence of the environment or its own synergy. This is a very slow process. But they can almost instantly mutate, significantly changing, it is very rare, even rarer mutations are fixed.

The most obvious feature of biological systems, as it is known, is that they are capable of self-organization, i.e. spontaneous formation and development of complex ordered structures. For the occurrence of the effects of selforganization requires a flow of energy coming into the system from an external source and dissipated it. Thanks to this thread becomes active, that is, acquires the ability to Autonomous formation of structures.

Since the main distinctive characteristic of these learning environments are proceeding in which the processes of self-organization, synergy can also be seen as a General theory of self-organization in environments of different nature.

Self-organization in General - the process of establishment of organization, of magnitude due to the coherent interaction of the components within the system in the absence of regulating influences from the external environment. Infinite alternating stages of adaptation - evolution and rebirth - revolution, which brings the system to new levels of excellence, and is, in essence, self-organization. For managers self-organization is an endless alternation of phases of "good" management, organizational work, adapting existing facilities to changes in the environment, and creative ideas, innovative solutions, inventions and "revolutionary" reorganizations, leading the system to a completely new level of perfection. These stages are the head, has found an ingenious solution, practically implements the various options for a possible future state of a particular system.

\section{Conclusions}

Thus, for a successful structuring of processes for management of enterprise development should follow a number of principles for the management of enterprise development based on integration, targeted, systematic, integrated, casebased and economic approach. Also added the principle of synergetic approach to managing effective enterprise development, which is inherent in the principles of self-organization and self-development systems, openness of the enterprise for innovation and transformation.

The main objective when managing effective enterprise development becomes the task of determining the causes and drivers of change, rather than to the essence and components of the existing system as it was previously accepted. 


\section{References}

Barmuta, K. A. 2010. The sustainable development of enterprises in the development of innovations. Bulletin of the don state technical University, № 8 (51). pp. 1274-1279.

Bogomolov, N.In. 2007. Modern features of the implementation strategy for the restructuring of enterprises of the defence industry: Eighth all-Russian Symposium "Strategic planning and development of enterprises". Moscow: CEMI RAS.

Kazantsev, A.K. 2008. Diagnosis of the national innovation system of Russia: state and development trends. Management of innovative and investment processes of formation and development of industrial enterprises, proc. The Intern. nauch.-practical use. Conf. 15-16 May 2008, SPb.: SPBGIEU.

Olufemi, D.D., Caleb A.A. \& Akinjare O.A. 2012 Strategic Management of Human Resources in the Health Care System. Mediterranean Journal of Social Sciences. MJSS Vol. 3, No. 1, January 2012. pp. 261-266.

Lefter, V. \& Brătianu C. 2001. Management strategic universitar, Ed. Rao, Bucureşti. 